\title{
LC-MS-based metabolomics revealed SLC25A22 as an essential regulator of aspartate-derived amino acids and polyamines in KRAS-mutant colorectal cancer
}

\author{
Xiaona $\mathrm{Li}^{1}$, Arthur C.K. Chung ${ }^{1}$, Shangfu $\mathrm{Li}^{1}$, Lilan $\mathrm{Wu}^{1,2}$, Jiaying $\mathrm{X} \mathbf{u}^{3}$, Jun $\mathrm{Yu}^{3,4}$, \\ Chichun Wong ${ }^{3,4}$ and Zongwei Cai ${ }^{1}$ \\ ${ }^{1}$ State Key Laboratory of Environmental and Biological Analysis, Department of Chemistry, Hong Kong Baptist University, \\ Hong Kong, China \\ ${ }^{2}$ Guangdong Provincial Academy of Chinese Medical Sciences, The Second Affiliated Hospital of Guangzhou University of \\ Chinese Medicine, Guangdong, China \\ ${ }^{3}$ Institute of Digestive Disease and Department of Medicine and Therapeutics, State Key Laboratory of Digestive Disease, Li \\ Ka Shing Institute of Health Sciences, Chinese University of Hong Kong, Hong Kong, China \\ ${ }^{4}$ Shenzhen Research Institute, The Chinese University of Hong Kong, Guangdong, China \\ Correspondence to: Zongwei Cai, email: zwcai@hkbu.edu.hk \\ Chichun Wong, email: chichun.wong@cuhk.edu.hk
}

Keywords: KRAS-mutant colorectal cancer, SLC25A22, LC-MS, metabolomics

Received: July 27, 2017 Accepted: September 04, $2017 \quad$ Published: September 20, 2017

Copyright: Li et al. This is an open-access article distributed under the terms of the Creative Commons Attribution License 3.0 (CC BY 3.0 ), which permits unrestricted use, distribution, and reproduction in any medium, provided the original author and source are credited.

\section{ABSTRACT}

SLC25A22, which encodes the mitochondrial glutamate transporter, is overexpressed in colorectal cancer (CRC) and is essential for the proliferation of CRC cells harboring KRAS mutations. However, the role of SLC25A22 on metabolic regulation in KRAS-mutant CRC cells has not been comprehensively characterized.

We performed non-targeted metabolomics, targeted metabolomics and isotope kinetic analysis of KRAS-mutant DLD1 cells with or without SLC25A22 knockdown using ultra-high-performance liquid chromatography (UHPLC) coupled to Orbitrap mass spectrometry (MS) or tandem MS (MS/MS).

Global metabolomics analysis identified 35 altered metabolites, which were attributed to alanine, aspartate and glutamate metabolism, urea cycle and polyamine metabolism. Targeted metabolomics including 24 metabolites revealed that most tricarboxylic acid (TCA) cycle intermediates, aspartate-derived asparagine, alanine and ornithine-derived polyamines were strongly down-regulated in SLC25A22 knockdown cells. Moreover, targeted kinetic isotope analysis showed that most of the ${ }^{13} \mathrm{C}$-labeled ornithine-derived polyamines were significantly decreased in SLC25A22 knockdown cells and culture medium. Exogenous addition of polyamines could significantly promote cell proliferation in DLD1 cells, highlighting their potential role as oncogenic metabolites that function downstream of SLC25A22-mediated glutamine metabolism.

Collectively, SLC25A22 acts as an essential metabolic regulator during CRC progression as it promotes the synthesis of aspartate-derived amino acids and polyamines in KRAS mutant CRC cells.

\section{INTRODUCTION}

Colorectal cancer (CRC) is the third most common cancer worldwide [1]. KRAS oncogene, mutated in approximately $30 \%-50 \%$ of CRC patients [2], presents both as a prognostic and predictive marker for targeted therapy of CRC $[3,4]$, and mutations in $K R A S$ results in non-response to anti-EGFR inhibitors [4-6]. In our previous study, we identified SLC25A22, which encodes a mitochondrial glutamate transporter, as a novel oncogene essential for 
the viability of $C R C$ cell lines with simultaneous mutations in $A P C$ or $C T N N B 1$ and KRAS [7]. SLC25A22 enhances cell proliferation and survival by promoting the synthesis of glutamine-derived aspartate (Asp). Apart from its role in CRC tumorigenesis, SLC25A22 has also been found to be mutated in encephalopathies, which frequently involved in altering the highly conserved amino acids that will completely abolish glutamate carrier activity $[8,9]$. However, the full spectrum of metabolic effects of SLC25A22 on KRAS-mutant CRC cell lines have not been comprehensively characterized.

Metabolomics analysis plays a crucial role in the discovery of potential metabolic biomarkers during development of drug and diagnosis, as well as in revealing gene function during cell metabolism [6, 11-13]. Global and targeted metabolomics, which respectively aims to profile the entire and specific components of the metabolome, provide signatures for various metabolic phenotype and aid in the understanding of the mechanism of action of drugs or genes in biological systems at the level of metabolites. Nuclear magnetic resonance (NMR) and mass spectrometry (MS) coupled to gas chromatography (GC) or liquid chromatography (LC) are mainly two approaches to identity and quantify the metabolome on a global scale $[14,15]$. NMR detection allows rapid detection, small sample volumes and provides structural information. However, the sensitivity and dynamic range of NMR are lower than MS [16]. Due to its high sensitivity and reproducibility, LC-MS-based metabolomics is a promising strategy to further elucidate metabolic pathways regulated by SLC25A22 in KRAS-mutant CRC and provide insights into the therapy of CRC with $K R A S$ mutation.

In the study, global and targeted metabolomics based on ultra-high-performance liquid chromatography coupled to mass spectrometry (UHPLC-MS) were utilized to evaluate the effects of SLC25A22 on cellular metabolism in KRAS-mutant CRC cells. The control (pLKO) and SLC25A22 knockdown (shSLC25A22) DLD1 cells were used. Moreover, targeted metabolomics analysis involving TCA cycle intermediates, amino acids and polyamines were conducted by triple-quadrupole (QqQ) MS. Finally, the metabolite fates of urea cycle intermediates and polyamines were traced via targeted kinetic analysis of DLD1 cells using $\left[\mathrm{U}_{-}{ }^{13} \mathrm{C}_{5}\right]$-glutamine as the isotope tracer. The workflow was shown in Figure 1. Our analyses revealed Asp-derived amino acids and polyamines as key oncogenic metabolites involved in SLC25A22-mediated cell proliferation in a CRC cell line with $K R A S$-mutation.

\section{RESULTS}

\section{Global metabolomics analysis by UHPLC- Orbitrap-MS analysis}

In the global metabolomics analysis, a total of 6,195 and 5,260 metabolic features were obtained in positive and negative ion mode, respectively (total ion chromatogram (TIC) shown in Supplementary Figure 1A). Among them,

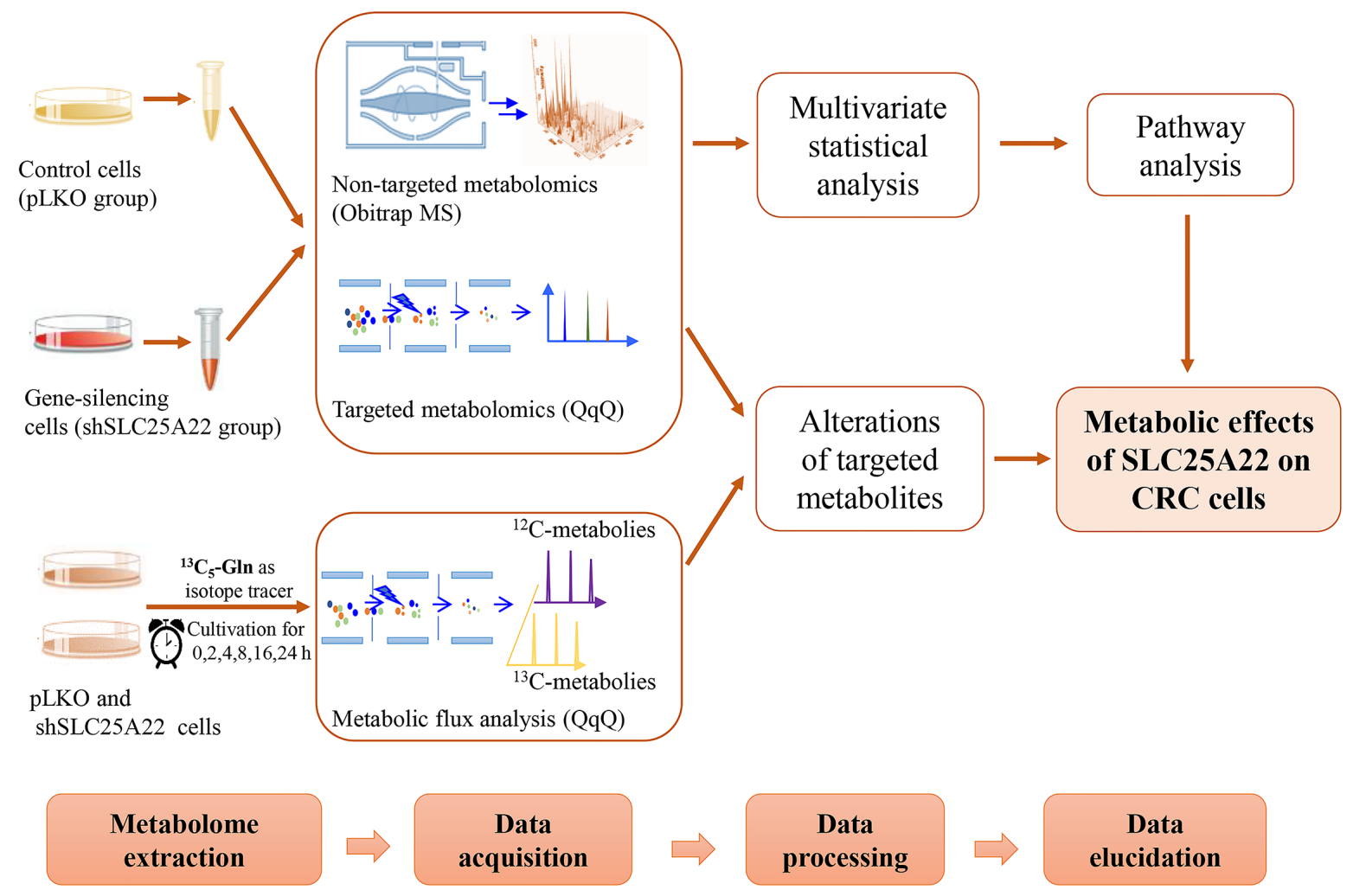

Figure 1: The workflow of global, targeted metabolomics analysis and kinetic isotope analysis. 
267 metabolites (175 in positive and 92 in negative mode) were identified. Eventually, we found 35 metabolites, out of which 16 were confirmed by comparing with authentic standards, were significantly altered with fold change (FC) of shSLC25A22/pLKO more than 1.1 or less than 0.8 ( $t$-test: $p<$ 0.05 ) through volcano plot screening (Supplementary Figure $1 \mathrm{~B}$ and $1 \mathrm{C}$ ) and VIP (variable importance in projection) over 1.0. The score plot in PLS-DA (partial least squaresdiscriminant analysis) model showed that shSLC25A22 cells were clearly separated from pLKO cells in positive and negative ion mode, respectively (Figure 2A and 2B).

Overall, specific sets of metabolites were altered considerably in shSLC25A22 cells compared to pLKO cells $(p<0.05)$, such as amino acids, nucleotides, carnitines, lipids, fatty acids, and their derivatives (Table 1). The pathway impact of alanine, aspartate and glutamate pathway over 0.6 demonstrated that metabolites, involving L-glutamine (Gln), L-glutamic acid (Glu), N-acetylaspartic acid (Ac-Asp), L-aspartic acid (Asp), L-asparagine (Asn) and L-alanine (Ala), made great contributions to the pathway analysis (Figure $2 \mathrm{C}$ ). The heatmap of top 15 significantly changed metabolites was shown in Figure 2D. The FC of Gln and Glu were $1.33\left(p=2.6 \mathrm{e}^{-5}\right)$ and $1.29\left(p=1.1 \mathrm{e}^{-4}\right)$ between shSLC25A22 and pLKO, while the FC of Asp and Ac-Asp were of 0.55 ( $p=2.4$ $\left.\mathrm{e}^{-8}\right)$ and $0.71\left(p=5.7 \mathrm{e}^{-13}\right)$, indicating reduced conversion from Gln and Glu to Asp or Ac-Asp, which was partially consistent with previous reports [7, 17]. Furthermore, Asp-derived metabolites, particularly asparagine and alanine, were down-regulated in SLC25A22-silenced cells (Asn, $\mathrm{FC}=0.79, p=9.8 \mathrm{e}^{-5}$; Ala, $\mathrm{FC}=0.75, p=$ $\left.4.2 \mathrm{e}^{-9}\right)$ as compared to DLD1-pLKO cells. AICAR (5-aminoimidazole-4-carboxyamide ribonucleoside) with the largest FC of $2.8\left(p=1.7 \mathrm{e}^{6}\right)$ is an activator of AMPactivated protein kinase (AMPK) pathway, which inhibits cancer cell growth [18, 19]. Additionally, enrichment analysis further demonstrated that altered metabolites were involved in protein synthesis, ammonia recycling, urea cycle, glutamate metabolism, glutathione metabolism and aspartate metabolism (Figure 2E), which further confirmed the importance of alanine, aspartate and glutamate metabolism, polyamine and urea cycle metabolism.
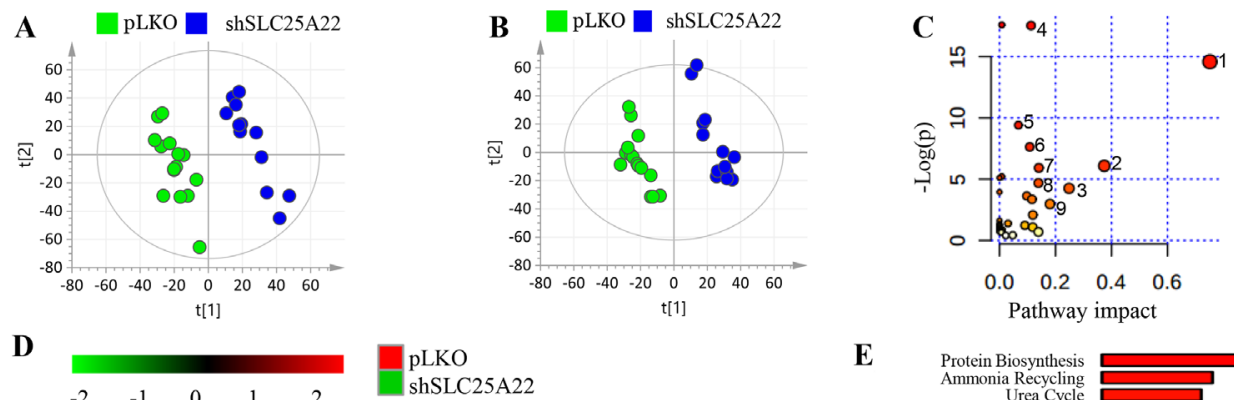

pLKO
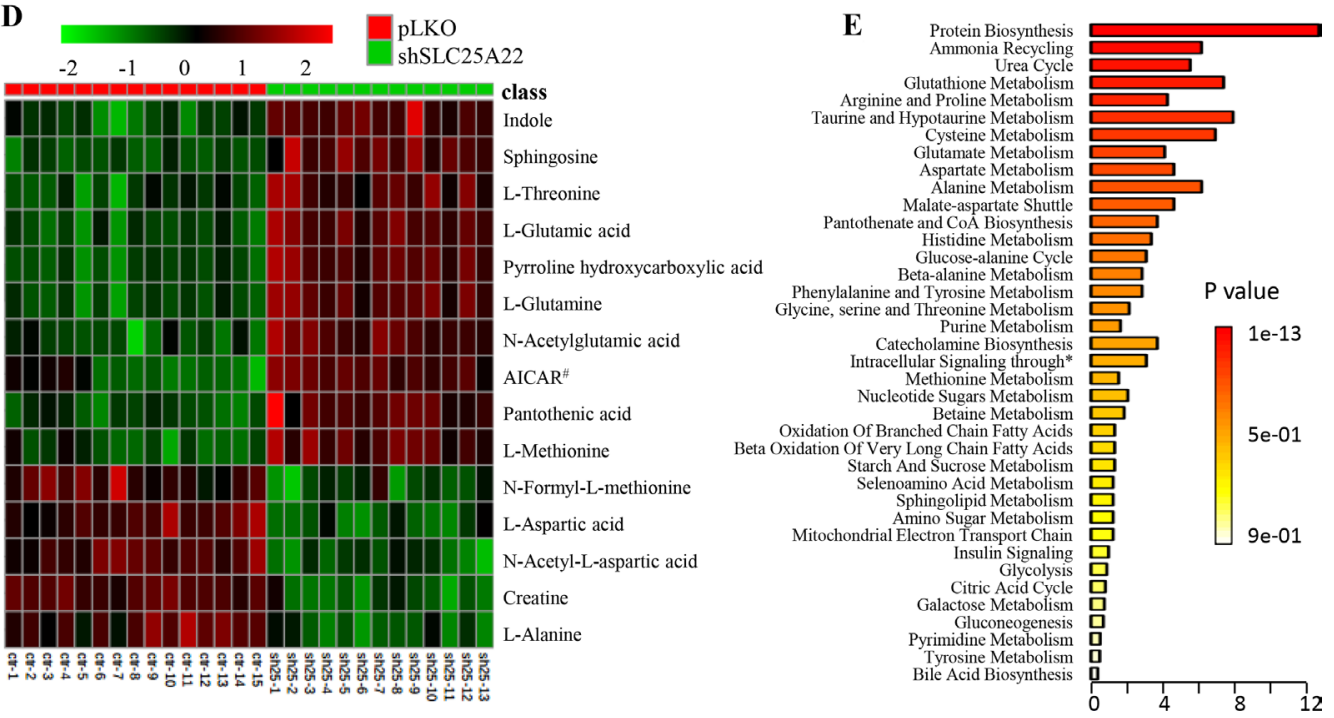

Figure 2: Global metabolic profiles of DLD1 cell line (KRAS-mutant CRC) stably expressing pLKO and shSLC25A22. (A) PLS-DA score plot in positive ion mode of LC-MS, showing clear separation between DLD1-pLKO cells (green dots) and DLD1shSLC25A22 cells (blue dots). [t1]: component 1, [t2]: component 2. (B) PLS-DA score plot in negative ion mode. (C) Pathway analysis revealed that the silencing of SLC25A22 made the greatest impact on alanine, aspartate and glutamate metabolism. 1: Alanine, aspartate and Glutamate metabolism; 2: Taurine and hypotaurine metabolism; 3: Glutathione metabolism; 4: Aminoacyl-tRNA biosynthesis; 5: Cysteine and methionine metabolism; 6: Arginine and proline metabolism; 7: Histidine metabolism, 8: D-Glutamine and D-glutamate metabolism; 9: Pantothenate and CoA biosynthesis. (D) A Heatmap showed the top 15 significantly changed metabolites. AICAR ${ }^{\#}$ represented 1-(5'-Phosphoribosyl)-5-amino-4-imidazolecarboxamide. (E) Enrichment analysis further showed top three important pathways, including protein biosynthesis, ammonia recycling and urea cycle. ${ }^{*}$ represented intracellular signaling through prostacyclin receptor and prostacyclin. 
Table 1: The list of identified metabolites changed significantly between shSLC25A22 and pLKO cell (in order of descending fold change)

\begin{tabular}{|c|c|c|c|c|c|c|c|c|c|}
\hline No. & Compound name & $\mathbf{m} / \mathbf{z}$ & $\mathrm{RT} / \mathrm{min}$ & $\mathrm{FC}(\mathbf{s} / \mathbf{p})^{\mathrm{a}}$ & $P$-value & MS Pattern & $\Delta p p m$ & Mode & Pathway \\
\hline 1 & $\mathrm{AICAR}^{\#}$ & 339.0680 & 1.51 & 2.82 & $1.7 \mathrm{E}-06$ & $110.0352,97.0283,127.0614$ & 6.0 & $+/-$ & $\begin{array}{l}\text { Histidine metabolism, purine } \\
\text { metabolism }\end{array}$ \\
\hline 2 & N-Acetylglutamic acid & 190.0699 & 2.09 & 1.60 & $9.9 \mathrm{E}-06$ & $190.0710,172.0600,130.0500$ & 5.8 & $+/-$ & Biosynthesis of amino acids \\
\hline 3 & Sphingosine & 300.2879 & 13.38 & 1.54 & $2.4 \mathrm{E}-06$ & $282.2783,252.2679,56.0497$ & 5.9 & + & Sphingosine metabolism \\
\hline 4 & L-Glutamine* & 147.0756 & 0.90 & 1.33 & $2.6 \mathrm{E}-05$ & $147.0762,130.0495,84.0448$ & 5.5 & + & $\begin{array}{l}\text { Alanine, aspartate and glutamate } \\
\text { metabolism }\end{array}$ \\
\hline 5 & $\begin{array}{l}\text { Pyrroline } \\
\text { hydroxycarboxylic acid }\end{array}$ & 130.0492 & 0.91 & 1.31 & $9.2 \mathrm{E}-05$ & $84.0447,130.0493,56.0505$ & 5.2 & + & Arginine and proline metabolism \\
\hline 6 & L-Glutamic acid* & 148.0595 & 0.92 & 1.29 & $1.1 \mathrm{E}-04$ & $84.0446,102.0547,130.0497$ & 6.3 & + & $\begin{array}{l}\text { Alanine, aspartate and glutamate } \\
\text { metabolism }\end{array}$ \\
\hline 7 & Glutathione* $^{*}$ & 308.0891 & 1.58 & 1.22 & $1.6 \mathrm{E}-02$ & $308.0934,233.0610,162.0235$ & 6.4 & $+/-$ & Glutathione metabolism \\
\hline 8 & Indole & 118.0644 & 6.05 & 1.21 & $6.9 \mathrm{E}-04$ & $118.0648,91.0540,65.0386$ & 6.0 & + & $\begin{array}{l}\text { Phenylalanine, tyrosine and } \\
\text { tryptophan metabolism }\end{array}$ \\
\hline 9 & L-Threonine* & 120.0649 & 0.91 & 1.17 & $3.6 \mathrm{E}-02$ & $56.0497,74.0599,102.0547$ & 5.5 & + & $\begin{array}{l}\text { Aminoacyl-tRNA biosynthesis, } \\
\text { threonine metabolism }\end{array}$ \\
\hline 10 & Glycerophosphocholine & 258.1086 & 0.91 & 1.15 & $1.4 \mathrm{E}-02$ & $104.1067,124.9995,184.0729$ & 5.8 & + & Glycerophopholipid metabolism \\
\hline 11 & L-Methionine" & 150.0575 & 1.53 & 1.13 & $1.1 \mathrm{E}-02$ & $150.0574,133.0314,104.0528$ & 5.5 & + & $\begin{array}{l}\text { Aminoacyl-tRNA biosynthesis, } \\
\text { Cysteine and methionine } \\
\text { metabolism }\end{array}$ \\
\hline 12 & Pantothenic acid" & 220.1167 & 4.79 & 1.10 & $3.2 \mathrm{E}-02$ & $90.0548,220.1175,202.1069$ & 5.9 & $+/-$ & $\begin{array}{l}\text { Pantothenate and CoA } \\
\text { biosynthesis }\end{array}$ \\
\hline 13 & Creatine ${ }^{*}$ & 132.0760 & 0.95 & 0.80 & $1.0 \mathrm{E}-10$ & $132.0768,90.0555,87.0557$ & 5.6 & $+/-$ & Arginine and proline metabolism \\
\hline 14 & Butyrylcarnitine & 232.1530 & 5.00 & 0.79 & $3.5 \mathrm{E}-03$ & $232.1565,173.0821,85.0295$ & 5.7 & + & Fatty acid oxidation \\
\hline 15 & L-Asparagine* & 133.0599 & 0.90 & 0.79 & $9.8 \mathrm{E}-05$ & $133.0602,87.0551,74.0242$ & 6.8 & + & $\begin{array}{l}\text { Alanine, aspartate and glutamate } \\
\text { metabolism }\end{array}$ \\
\hline 16 & L-Histidine" & 154.0612 & 0.86 & 0.78 & $1.2 \mathrm{E}-04$ & $154.0613,93.0446,137.0346$ & 6.5 & - & $\begin{array}{l}\text { Aminoacyl-tRNA biosynthesis, } \\
\text { histidine metabolism }\end{array}$ \\
\hline 17 & $\begin{array}{l}\text { L-gamma-glutamyl-L- } \\
\text { leucine }\end{array}$ & 261.1430 & 5.56 & 0.78 & $8.2 \mathrm{E}-07$ & $261.1450,198.1120,132.1020$ & 5.9 & + & Biosynthesis of amino acids \\
\hline 18 & Xanthine & 151.0252 & 2.04 & 0.78 & $1.2 \mathrm{E}-02$ & $151.0250,108.0199$ & 6.4 & - & Purine metabolism \\
\hline 19 & $\mathrm{ADP}^{*}$ & 426.0227 & 1.48 & 0.78 & 7.3E-03 & $426.0227,158.9245,78.9575$ & 1.4 & - & Purine metabolism \\
\hline 20 & L-Tyrosine ${ }^{*}$ & 180.0659 & 4.28 & 0.77 & $5.0 \mathrm{E}-08$ & $119.0490,180.0659,136.0757$ & 3.9 & - & $\begin{array}{l}\text { Aminoacyl-tRNA biosynthesis, } \\
\text { tyrosine metabolism }\end{array}$ \\
\hline 21 & L-Phenylalanine* & 164.0706 & 4.28 & 0.77 & $7.0 \mathrm{E}-08$ & $147.0442,164.0707,72.0080$ & 6.9 & - & $\begin{array}{l}\text { Aminoacyl-tRNA biosynthesis, } \\
\text { phenylalanine metabolism }\end{array}$ \\
\hline 22 & N-Acetyl-L-methionine & 190.0538 & 5.68 & 0.77 & $1.7 \mathrm{E}-06$ & $148.0428,142.0499,190.0537$ & 2.7 & - & Protein biosynthesis \\
\hline 23 & $\begin{array}{l}\mathrm{N}^{1}, \mathrm{~N}^{12}- \\
\text { Diacetylspermine* }\end{array}$ & 287.2440 & 0.91 & 0.76 & $2.4 \mathrm{E}-02$ & $100.0763,171.1498$ & 0.5 & & Polyamine metabolism \\
\hline 24 & $\begin{array}{l}\text { Gamma } \\
\text { Glutamylglutamic acid }\end{array}$ & 277.1014 & 1.51 & 0.76 & $5.5 \mathrm{E}-03$ & $84.0442,148.0600,130.0496$ & 5.9 & + & $\begin{array}{l}\text { Amino acids biosynthesis and } \\
\text { metabolism }\end{array}$ \\
\hline 25 & $\begin{array}{l}\text { Uridine diphosphate } \\
\text { glucose }\end{array}$ & 565.0485 & 1.75 & 0.75 & $3.6 \mathrm{E}-02$ & $323.0290,565.0483,384.9848$ & 1.4 & - & Nuclear sugar metabolism \\
\hline 26 & $\begin{array}{l}\text { N-Formyl-L- } \\
\text { methionine }\end{array}$ & 176.0380 & 5.31 & 0.75 & $3.5 \mathrm{E}-11$ & $98.0234,128.0342,176.0379$ & 4.1 & - & $\begin{array}{l}\text { Cysteine and methionine } \\
\text { metabolism }\end{array}$ \\
\hline 27 & L-Acetylcarnitine & 204.1219 & 1.51 & 0.75 & $8.9 \mathrm{E}-08$ & $85.0282,204.1227,60.0809$ & 5.5 & + & Fatty acid oxidation \\
\hline 28 & L-Alanine* & 90.0545 & 0.90 & 0.75 & 4.2E-09 & 90.0544 & 5.3 & + & $\begin{array}{l}\text { Alanine, aspartate and glutamate } \\
\text { metabolism }\end{array}$ \\
\hline 29 & Oxidized glutathione* & 613.1558 & 2.43 & 0.74 & $5.0 \mathrm{E}-02$ & $613.1592,538.1252,484.1162$ & 5.7 & $+/-$ & Glutathione metabolism \\
\hline 30 & $\begin{array}{l}\text { N-Acetyl-L-aspartic } \\
\text { acid }\end{array}$ & 174.0399 & 1.01 & 0.71 & $5.7 \mathrm{E}-13$ & $88.0390,130.0499,58.0282$ & 5.1 & - & $\begin{array}{l}\text { Alanine, aspartate and glutamate } \\
\text { metabolism }\end{array}$ \\
\hline
\end{tabular}




\begin{tabular}{|c|c|c|c|c|c|c|c|c|c|}
\hline 31 & $\begin{array}{l}\text { Gamma- } \\
\text { Glutamyltyrosine }\end{array}$ & 311.1219 & 4.76 & 0.69 & $8.5 \mathrm{E}-08$ & $311.1240,248.0920,182.0810$ & 6.0 & + & Tyrosine metabolism \\
\hline 32 & $\begin{array}{l}\text { Uridine diphosphate- } \\
\mathrm{N} \text {-acetylglucosamine }\end{array}$ & 606.0754 & 2.67 & 0.69 & 4.7E-04 & $606.0750,384.9849,282.0388$ & 1.8 & - & Nucleotide biosynthesis \\
\hline 33 & L-Aspartic acid* & 132.0291 & 0.90 & 0.55 & 2.4E-08 & $132.0291,115.0025,88.0399$ & 8.7 & - & $\begin{array}{l}\text { Alanine, aspartate and glutamate } \\
\text { metabolism }\end{array}$ \\
\hline 34 & Taurine & 126.0213 & 0.91 & 0.49 & $1.9 \mathrm{E}-06$ & $126.0214,108.0109$ & 5.4 & $+/-$ & $\begin{array}{l}\text { Taurine and hypotaurine } \\
\text { metabolism }\end{array}$ \\
\hline 35 & 3-Sulfinoalanine & 152.0013 & 0.92 & 0.48 & $1.9 \mathrm{E}-03$ & $88.0390,152.0017$ & 6.7 & - & $\begin{array}{l}\text { Taurine and hypotaurine } \\
\text { metabolism }\end{array}$ \\
\hline
\end{tabular}

Notes:

${ }^{\mathrm{a}} \mathrm{FC}(\mathrm{s} / \mathrm{p})$ represented fold change between shSLC25A22 and pLKO cells

${ }^{\mathrm{b}} \mathrm{AAs}$ and derivatives represented that amino acids and their derivatives.

"Represented the metabolite was identified by authentic standard and database, while the unmarked metabolite was identified by database

\#AICAR, 1-(5'-Phosphoribosyl)-5-amino-4-imidazolecarboxamide.

\section{Targeted metabolomics analysis by UHPLC- QqQ analysis}

Gln serves as carbon and nitrogen source in cells. Gln is converted into Glu by removing one molecule of amide group, followed by entry into TCA cycle to generate Asp and Asp-derived amino acids, which belongs to the alanine, aspartate and glutamate metabolism (Figure 3A in green). On the other hand, Gln also participates in nitrogen metabolism including urea cycle and polyamine biosynthesis [20, 21] (Figure 3A in blue). Targeted analysis was thus performed on these metabolic pathways.

As shown in Supplementary Figure 2A, when the expression of SLC25A22 was knocked down in DLD1shSLC25A22 cells, TCA cycle intermediates tended to be down-regulated, especially malate $(p<0.05)$ and fumarate $(p<0.05)$, which was in agreement with our previous study [7]. The relative ratio of up- and down-stream amino acids in alanine, aspartate and glutamate metabolism between shSLC25A22 cells and pLKO cells showed that Asp was close to $0.5(p<0.001)$, indicating strong reduction of this metabolite in SLC25A22 silenced cells. Moreover, levels of Ala, Asn and Gly were significantly reduced in shSLC25A22 cells, which were likely a consequence of reduced Asp levels (Figure 3B). Level of SLC25A22 expression in cells did not affect Gln, Glu, Ser and Pro differentially.

Urea cycle metabolites such as ornithine (Orn), citrulline (Citr) and arginine (Arg) were not significantly altered except for Asp, which functions as an intermediate to generate arginosuccinate (Supplementary Figure 2B). On the other hand, Orn-derived polyamines putrescine (Put, $p<0.05$ ), spermine (Spm, $p<0.05$ ) and acetylated polyamines, involving $N^{l}$-acetylputrescine (AcPut, $p<0.01$ ), $N^{l}$-acetylspermidine (AcSpd, $p<0.001$ ), $N^{1}$-acetylspermine (AcSpm, $p<0.01$ ), and $N^{1}, N^{12}$ diacetylspermine (DAS, $p<0.05$ ) were suppressed in DLD1-shSLC25A22 cells (Figure 3C). These data indicated that knockdown of SLC25A22 expression profoundly affected TCA cycle and aspartate, an intermediate of urea cycle, whilst other urea cycle intermediates were not changed significantly, leading to reduced levels of TCA cycle intermediates, Asp-related amino acids and polyamines.

\section{Metabolic kinetic isotope analysis by UHPLC- QqQ-MS with [ $\left.\mathrm{U}^{13} \mathrm{C}_{5}\right]$-glutamine as isotope tracer}

We next traced the metabolic fates of Asp-derived amino acids and polyamines using $\left[\mathrm{U}_{-}{ }^{13} \mathrm{C}_{5}\right]$-glutamine as isotope tracer. ${ }^{13} \mathrm{C}_{4}$-Asp, ${ }^{13} \mathrm{C}_{4}$-Asn and ${ }^{13} \mathrm{C}_{3}$-Ala were labelled using $\left[\mathrm{U}^{13} \mathrm{C}_{5}\right]$-Gln as carbon source (Figure 4A) [22]. Results demonstrated that ${ }^{13} \mathrm{C}$-labled Asp, Asn and Ala were significantly reduced in DLD1-shSLC25A22 cells in comparison with those in the control DLD1pLKO cells at time points starting from $4 \mathrm{~h}(p<0.05)$ (Figure 4B). Of note, the intensity of $\left[\mathrm{U}_{-}{ }^{13} \mathrm{C}_{3}\right]$-Ala in DLD1-shSLC25A22 cells at each time point was close to 0.5-fold compared to that in control DLD1-pLKO cells, indicating a strong reduction in the levels of this metabolite. Moreover, tendencies of ${ }^{12} \mathrm{C}$-metabolites were similar with ${ }^{13} \mathrm{C}$-metabolites (Supplementary Figure 3A and 3B), suggesting that SLC25A22-mediated glutamine metabolism is important for the biosynthesis of these amino acids.

The $\left[\mathrm{U}-{ }^{13} \mathrm{C}_{5}\right]$-ornithine in urea cycle derived from $\left[\mathrm{U}-{ }^{13} \mathrm{C}_{5}\right]$-Gln can be converted into $\left[\mathrm{U}-{ }^{13} \mathrm{C}_{4}\right]-\mathrm{Put}$ via ornithine decarboxylase $(O D C)$ and then further metabolized into Spd and Spm, which are acetylated and exported via passive diffusion across the cell membrane (Figure 4C) [23]. [U- ${ }^{13} \mathrm{C}_{5}$ ]-Orn were reduced in DLD1shSLC25A22 cells compared with DLD1-pLKO cells before $2 \mathrm{~h}$, while being up-regulated from $4 \mathrm{~h}$ to $24 \mathrm{~h}$; however, other ${ }^{13} \mathrm{C}_{5}$-urea cycle intermediates were not detected both in DLD1-pLKO and DLD1-shSLC25A22 cells (Figure 4D). On the other hand, all the ${ }^{13} \mathrm{C}_{4}-$ polyamine intermediates, with the exception of ${ }^{13} \mathrm{C}_{4}$ - AcPut at $4 \mathrm{~h}$, were down-regulated in the SLC25A22 knockdown cells $\left({ }^{13} \mathrm{C}_{4}\right.$-AcSpm and ${ }^{13} \mathrm{C}_{4}$-DAS were not detected). Of note, both ${ }^{12} \mathrm{C} /{ }^{13} \mathrm{C}$-polyamines in the DLD1-shSLC25A22 
cells and DLD1-shSLC25A22 conditioned cell culture media were significantly reduced compared to DLD1pLKO cells (Supplementary Figure 3C and 3D). These data indicated that silencing of SLC25A22 significantly impaired the flux of Gln-derived carbons into polyamine biosynthesis.

\section{Western blot analysis and mRNA expression of polyamine biosynthetic enzymes}

We validated whether the altered polyamine metabolism might be due to deregulated expression of enzymes involved in polyamine biosynthesis. However, western blot analysis revealed that $O D C$ expression was not significant different in SLC25A22-silenced DLD1 cells; whilst expression of spermidine/spermine $N^{1}$ acetyltransferase 1 (SAT1) was induced by knockdown of SLC25A22 (Figure 5A). Relative mRNA expression of ODC was not significantly different between control and SLC25A22-silenced cells in KRAS-mutant DLD1, HCT116, SW1116 cell line, while mRNA expression of SAT1 was dramatically increased in SLC25A22-silenced cells compared with control cells (Figure 5B); which was consistent with the results of western blot. This suggests that the suppression of polyamines biosynthesis is likely a direct consequence of reduced glutamine flux, but not influenced by changes in gene expression. We thus speculated that induced SAT1 expression might reflect an attempt to up-regulate polyamine metabolism in order to compensate for the reduced carbon flux from glutamine.

\section{Role of polyamines in the proliferation of $K R A S$ - mutant CRC cells}

Finally, we examined whether polyamines play a role in cell proliferation in $K R A S$-mutant CRC cells. We incubated DLD1 cells with six polyamines at 1.25/2.5 $\mu \mathrm{M}$ or $2.5 / 5 \mu \mathrm{M}$, and then examination cell viability by MTT assay. Our results showed that $N^{I}$-AcPut and $N^{1}$-AcSpd promoted CRC cell growth at both doses (Figure 5C).

\section{DISCUSSION}

Due to the wide dynamic range and reproducible analysis, UHPLC-MS is a powerful tool for metabolomics and capable of systematic profiling of endogenous metabolites and uncovering the complex metabolic
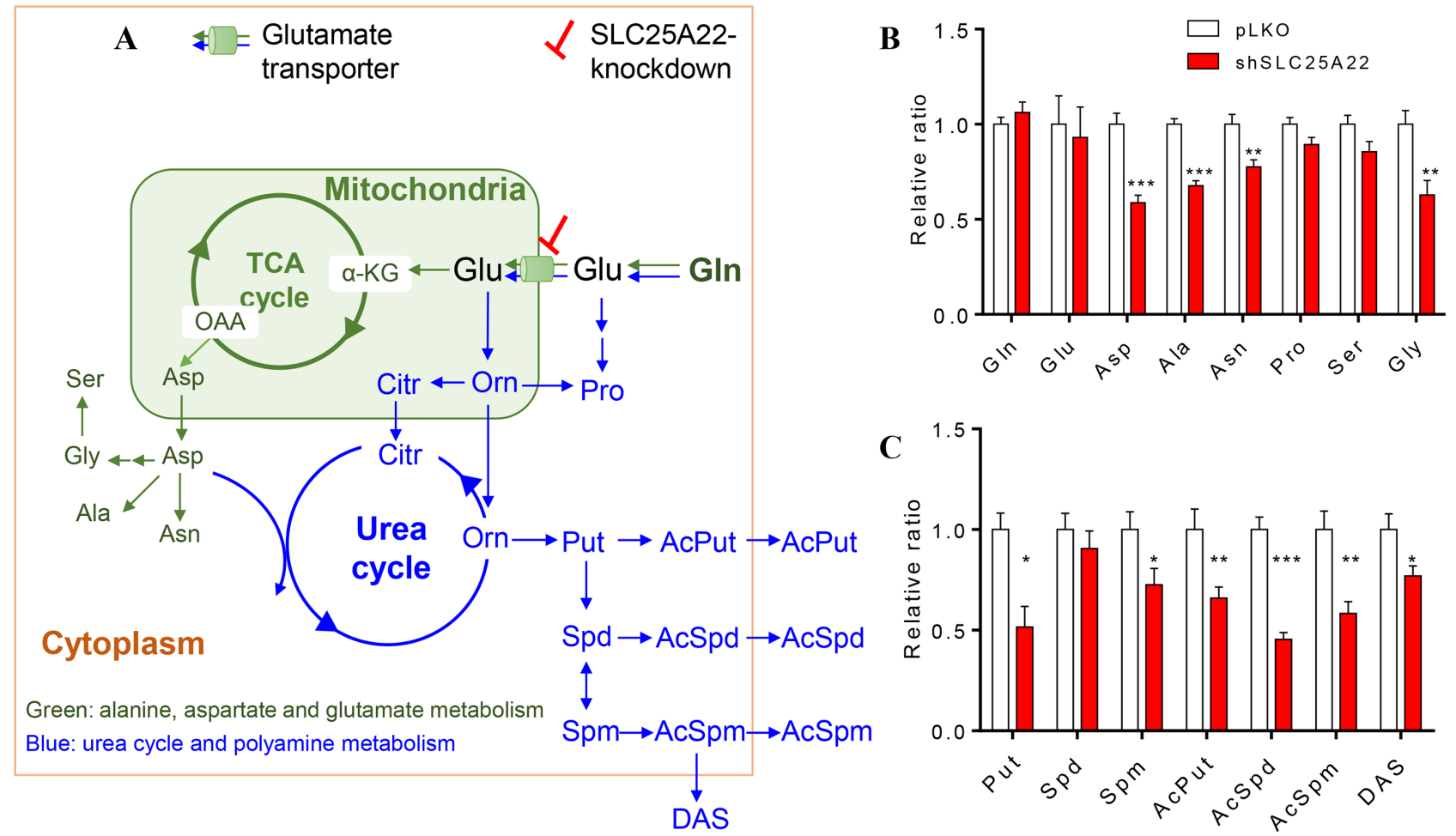

Figure 3: Targeted metabolomics metabolites between pLKO and shSLC25A22 cells. (A) Scheme overview of glutamine metabolism in mitochondria and cytoplasm. The green arrows and metabolites represented the alanine, aspartate and glutamate metabolism, the blue arrows and metabolites represented the urea cycle and polyamine metabolism. (B) Relative ratio of amino acids in alanine, glutamate and aspartate pathway between $\mathrm{pLKO}$ and shSLC25A22 cells, (C) Relative ratio of polyamines between pLKO and shSLC25A22 cells. ${ }^{*} p<0.05,{ }^{* *} p<0.01$, and ${ }^{* * *} p<0.001$. Error bar represented the SEM. Gln: glutamine, Glu, glutamate, $\alpha-K G: \alpha-k e t o g l u t a r a t e$, OAA: oxaloacetate, Asp: aspartate, Asn: asparagine, Ala: alanine, Pro: proline, Ser: serine, Gly: glycine, Orn: Ornithine, Citr: citrulline, Put: putrescine, Spd: spermidine, Spm: spermine, AcPut: $N^{I}$-Acetylputrescine, AcSpd: $N^{I}$-Acetylspermidine, AcSpm: $N 1$-Acetylspermine, DAS: $N^{l}, N^{12}$-Diacetylspermine. 
alterations that arise from gene mutation or aberrant gene expression $[24,25]$. In the study, 15 DLD1-pLKO and 13 DLD1-shSLC25A22 cell extracts by chilled $80 \% \mathrm{MeOH}$ were analyzed for global and targeted metabolomics analysis [26].

Compared shSLC25A22 cells to pLKO cells, global metabolomics analysis uncovered significantly altered amino acids were attributed to the alanine, aspartate and glutamate pathway. The findings were further confirmed by targeted analysis, which was complement with previous studies [7]. Some metabolites such as TCA cycle and urea cycle intermediates, nucleotides were found to be upregulated in CRC patients [27, 28]. Particularly, specific amino acids were regulated differentially in colorectal
$\mathbf{A}$

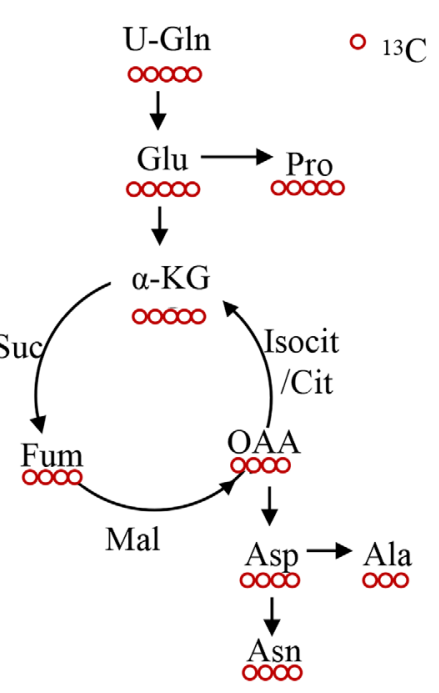

C

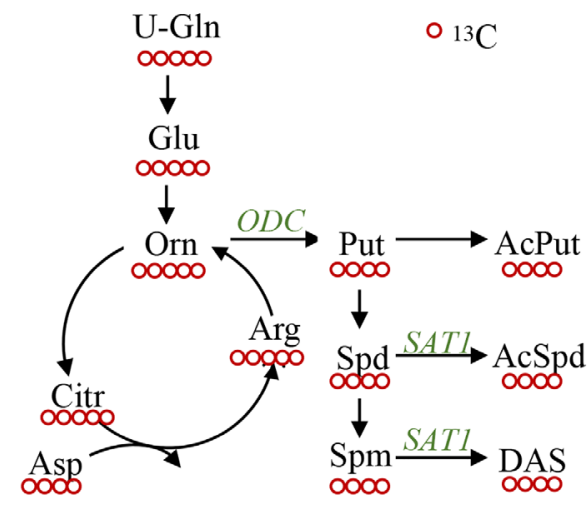

B $\rightarrow \mathrm{pLKO}$
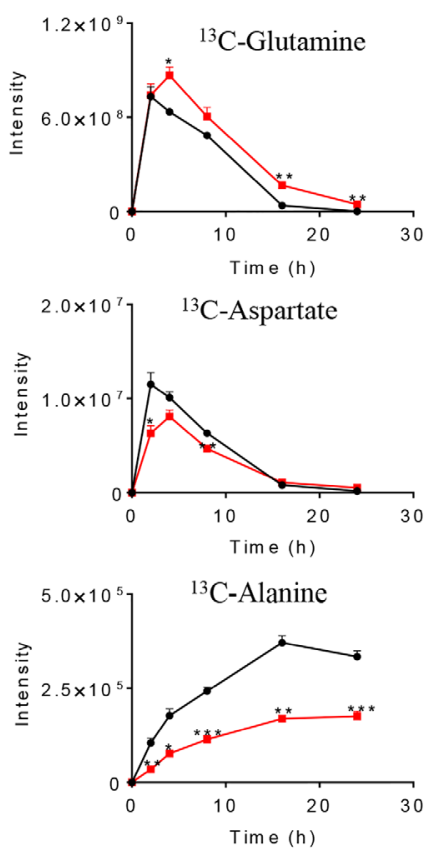

D
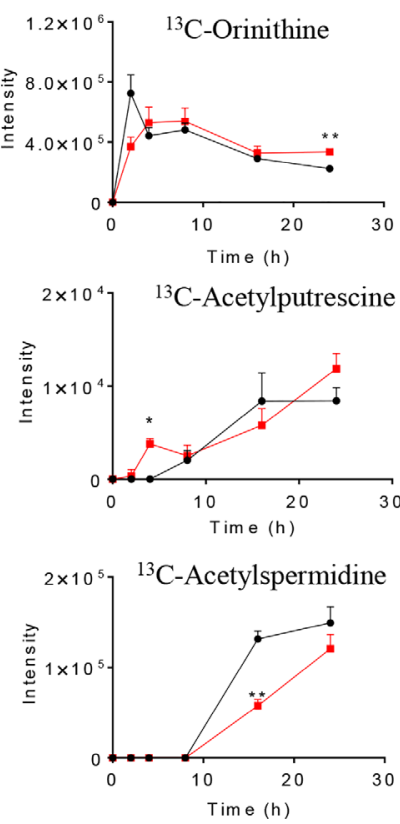

shSLC25A22
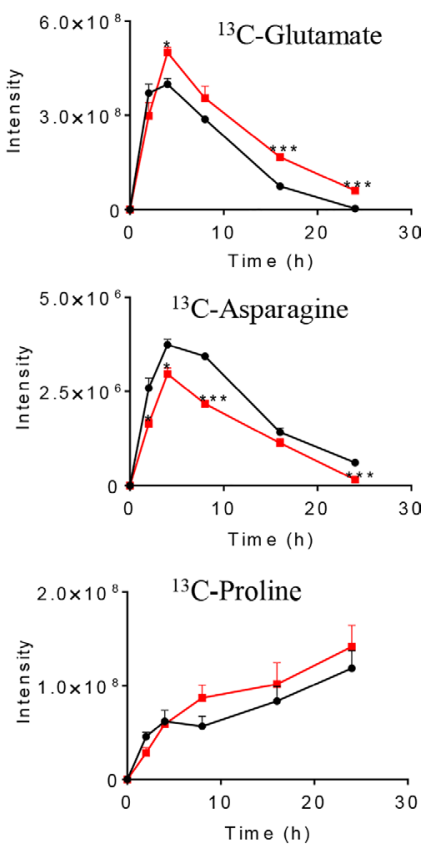

shSLC25A22
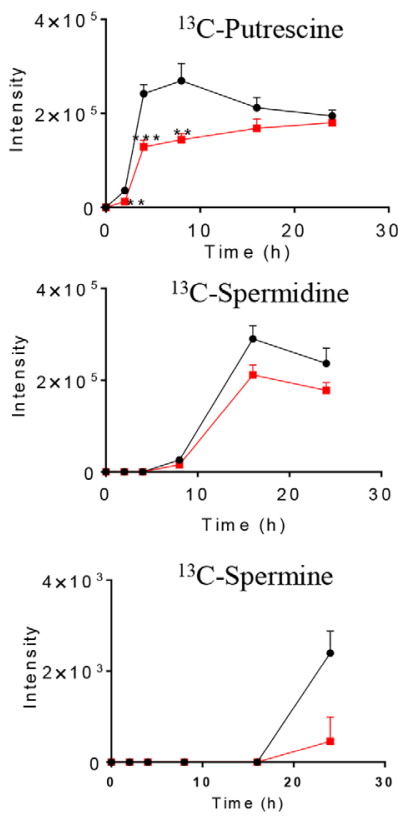

Figure 4: SLC25A22 knockdown inhibited polyamine biosynthesis but not triggered urea cycle in $K R A S$-mutant CRC cells. (A) Schematic overview of metabolism of downstream ${ }^{13} \mathrm{C}$-labeled amino acids sourced from ${ }^{13} \mathrm{C}_{5}$-glutamine; (B) Flux of ${ }^{13} \mathrm{C}$-Gln derived amino acids in shSLC25A22 and pLKO cells; (C) Schematic overview of metabolism in urea cycle and polyamines from ${ }^{13} \mathrm{C}_{5}-$ glutamine; (D) Flux of ${ }^{13} \mathrm{C}$-labeled urea cycle intermediates and ${ }^{13} \mathrm{C}_{4}$-polyamines in shSLC25A22 and pLKO cells. 
tissues of cancer patients. Ala, Asp, Gly, Pro and Ser were up-regulated, whilst Gln and Glu were down-regulated in CRC compared with healthy controls [29]. Ala was reported to function as alterative carbon source that fuels tumor metabolism [30]. Asn was shown to be upregulated in $K R A S$-mutant $\mathrm{CRC}$ via the overexpression of asparagine synthetase (ANSN) and it promotes protein biosynthesis in cancer cells by serving as an amino acid exchange factor regulates the uptake of amino acid and cell proliferation $[31,32]$. Consistent with the oncogenic function of SLC25A22 in CRC, knockdown of SLC25A22 down-regulated the biosynthesis of TCA cycle metabolites and Asp-derived amino acids (Ala, Asp and Gly) that are up-regulated in CRC, which in turn, impair KRAS-mutant CRC cell growth.

Apart from these aforementioned metabolites, we unveiled that SLC25A22 knockdown had a profound impact on polyamine metabolism. Polyamines derived from ornithine are required for normal and cancer cells [23, 33], and their levels are frequently upregulated in carcinogenesis. Johnson et al. found that polyamines, especially DAS as an end-product of polyamine metabolism, was strongly up-regulated in CRC tumor tissues compared to adjacent normal tissues using metabolomics approaches [13]. Here, our global metabolomics analysis showed that DAS was reduced in SLC25A22 knockdown cells $\left(\mathrm{FC}=0.76, P=2.4 \mathrm{e}^{-2}\right)$. Consequently, targeted analysis on polyamines and urea cycle metabolites demonstrated that polyamines were remarkably decreased in DLD1-shSLC25A22 cells. However, urea cycle intermediates were not sufficiently labelled by $\left[\mathrm{U}_{-}{ }^{13} \mathrm{C}_{5}\right]$-glutamine to enable detailed kinetic analysis of the urea cycle, suggesting the urea cycle did not trigger by the knockdown of SLC25A22. Previous reports indicated that increased polyamine metabolism could enhance cancer growth, migration and metastasis
$[34,35]$, while polyamines depletion could inhibit cancer cell proliferation, migration and invasion via SAT1 mediation [36]. Exogenous addition of some polyamine metabolites promoted growth of DLD1 cells, which confirmed their potential role as onco-metabolites in $K R A S$-mutant CRC. Taken together, SLC25A22-induced production of polyamines represents a novel mechanism whereby SLC25A22 mediates its oncogenic effect in KRAS-mutant CRC.

In summary, the data obtained through LC-MSbased global metabolomics, targeted metabolomics and kinetic isotope analysis indicated that SLC25A22 knockdown inhibited the biosynthesis of Asp-derived amino acids and polyamines in $K R A S$-mutant CRC cells. Furthermore, the addition of polyamine into culture medium can modulate CRC cell growth. Thus, our studies demonstrated that SLC25A22 is an essential regulator of the metabolic system of $K R A S$-mutant colorectal tumor and its overexpression promotes tumor cell growth, which could provide more insights into KRAS-mutant CRC therapy with treatment of polyamine-inhibitor.

\section{MATERIALS AND METHODS}

\section{Chemicals and reagents}

Pure water was prepared by Mili-Q system (Milipore, USA). Methanol (MeOH), acetonitrile $(\mathrm{ACN})$, formic acid (FA), ammonium hydroxide and ammonium acetate were of LC grade. All standards of (D/L-) amino acids, putrescine, spermidine, spermine, $N^{I}$ acetylputrescine and $N^{1-}$ acetylspermidine were purchased from Sigma (St. Lous, US). $N^{1}$-acetylspermine, $N^{1}, N^{12}$ diacetylspermine were ordered from Cayman (MI, US). $\left[\mathrm{U}-{ }^{13} \mathrm{C}_{5}\right]$-glutamine was obtained from Cambridge isotope laboratory (MA, US).
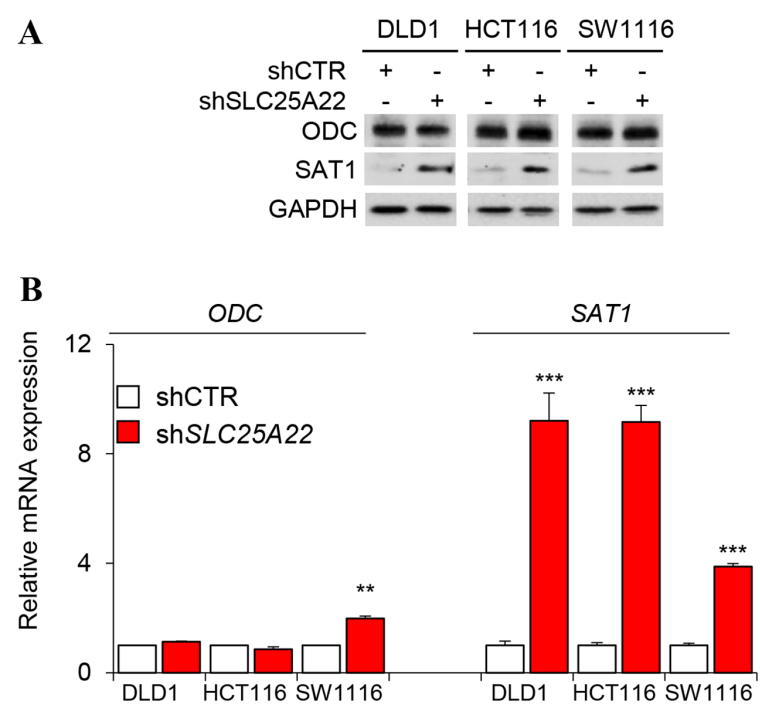

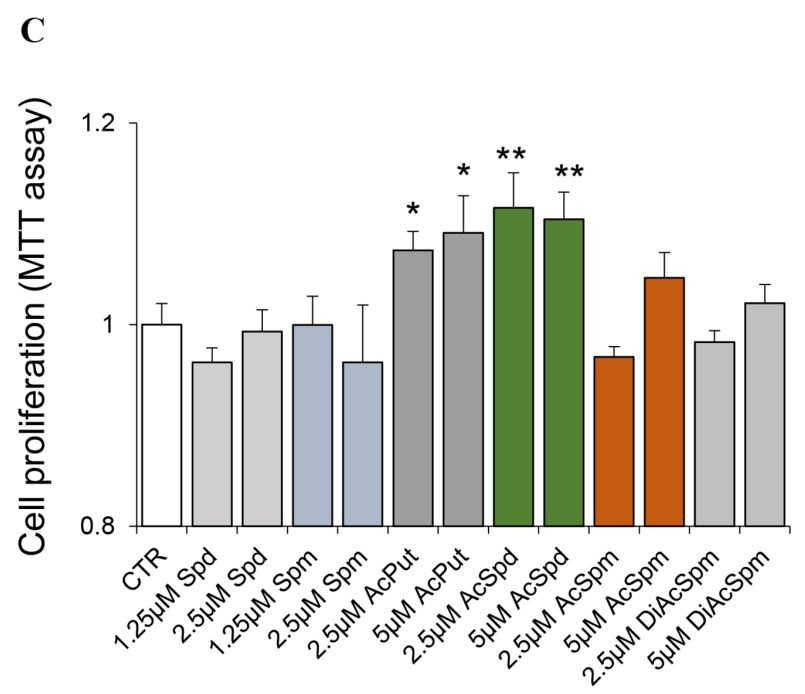

Figure 5: Western blot, qPCR and MTT analysis. (A) Western blot of ODC and SAT1 in shSLC25A22 and pLKO cells; (B) mRNA expression in qPCR analysis; (C) Cell proliferation in MTT assay. ${ }^{*} p<0.05,{ }^{* *} p<0.01$, and ${ }^{* * *} p<0.001$. Error bar represented the SEM. 


\section{Cell culture}

DLD1 cell line was obtained from American Type Culture Collection (ATCC, Rockville, MD). All cells were routinely cultured in the Dulbecco's modified eagle's medium (DMEM) medium supplemented with $10 \%$ fetal bovine serum (FBS) and 100 unit $/ \mathrm{mL}$ penicillin-streptomycin. DLD1 cells stably expressing pLKO (control, $n=15$ ) and shSLC25A22 (SLC25A22 knockdown, $n=13$ ) were cultured in the presence of puromycin $(2 \mu \mathrm{g} / \mathrm{mL})$. Cells were seeded at $5 \times 10^{6}$ per 10 $\mathrm{cm}$ dish for $24 \mathrm{~h}$ prior to global and targeted metabolomics analysis.

For targeted kinetic isotope analysis, DLD1-pLKO and DLD1-shSLC25A22 cell lines were seeded at a density of $2 \times 10^{6}$ cells $/ 10 \mathrm{~cm}$ dish in complete DMEM in triplicates. After $24 \mathrm{~h}$, the medium was replaced with glutamine-free MEM consisting of $2 \mathrm{mM}\left[{ }^{13} \mathrm{C}_{5}\right]$-glutamine. The cells were harvested at the following time points: $0 \mathrm{~h}$, $2 \mathrm{~h}, 4 \mathrm{~h}, 8 \mathrm{~h}, 16 \mathrm{~h}$ and $24 \mathrm{~h}$.

\section{Sample preparation}

Culture medium was aspirated and the cells were washed twice in ice-cold PBS and once in pure water. The cells were extracted by adding $1 \mathrm{~mL}$ chilled methanol: $\mathrm{H}_{2} \mathrm{O}(\mathrm{v} / \mathrm{v}, 8: 2)$ containing $0.1 \mu \mathrm{g} / \mathrm{mL}$ 4-chlorophenylalanine (4-Cl-Phe) as the internal standard (IS). The cells were then incubated at $-80{ }^{\circ} \mathrm{C}$ for $60 \mathrm{~min}$, scraped and transferred into Eppendorf tubes. Cell extracts were subjected to three freeze-thaw cycles using liquid nitrogen and ice. The supernatant was transferred into a new tube after centrifugation for $10 \mathrm{~min}$ at $16000 \mathrm{~g}, 4^{\circ} \mathrm{C}$. The residue was then extracted with $0.5 \mathrm{~mL}$ methanol, and the supernatants were pooled for lyophilization. The residues were stored at $-80^{\circ} \mathrm{C}$ prior to analyses.

Samples were reconstituted in $200 \mu \mathrm{L} \mathrm{MeOH}: \mathrm{H}_{2} \mathrm{O}$ (v/v, 85:15); $100 \mu \mathrm{L}$ was diluted to $50 \% \mathrm{MeOH}(\mathrm{v} / \mathrm{v})$ in water for non-targeted metabolomics study, followed by $30 \mu \mathrm{L}$ pooled together from each participant as a quality control (QC) sample; and the other $100 \mu \mathrm{L}$ for targeted metabolomics. All samples were detected within $24 \mathrm{~h}$ of reconstitution.

\section{Data acquisition of global metabolomics}

The data was acquired from Ultimate 3000 rapid separation liquid chromatography (RSLC) coupled with Q Exactive Focus MS (Thermo Scientific, USA) for global metabolomics analysis. The Acquity UPLC HSS

T3 $(2.1 \times 100 \mathrm{~mm}, 1.8 \mu \mathrm{m}$, Waters $)$ was used to separate metabolites at $30^{\circ} \mathrm{C}$. The mobile phases were water (A) and $\mathrm{ACN}(\mathrm{B})$, both with $0.1 \% \mathrm{FA}(\mathrm{v} / \mathrm{v})$. The injection volume was $10 \mu \mathrm{L}$. Data was acquired both in positive and negative ion mode. Specific LC-MS parameters were detailed in Supplemental Information. Cell samples were analyzed at random, and the sequence was performed in a "3 samples-1 QC" order after 3 QC samples. The QC sample was applied for analytical quality assurance and signal correlation [37].

\section{Data processing and metabolites identification of global metabolomics}

The raw data from metabolic profiling acquired in UHPLC-Orbitrap-MS was first converted into CDF data format by using Xcalibur workstation (Thermo Scientific, USA), and metabolic features were extracted by running XCMS package under R version 3.2.2 with chromatographic alignment and matching [38]. The noise level of global metabolomics data of XCMS parameters was set at 50,000 in positive and 20,000 in negative ion mode, respectively. Subsequently, a three-dimensional csv-format document involving $\mathrm{m} / \mathrm{z}$, retention time (RT) and peak intensity were obtained. Next, data was filtered using " $80 \%$ rule" [39], and normalized by the IS and protein content. Finally, the data was subjected to multivariate statistical analysis by SIMCA-P 13.0 (Umetrics, Sweden) after mean-centering and scaling to the standard deviation.

The potential biomarkers were identified by comparing exact $m / z$, retention time and MS/MS pattern of samples with those of authentic standards or those in database, such as Metlin (https://metlin.scripps.edu) and human metabolome database (HMDB, http://www.hmdb. ca) [40]. We applied $10 \mathrm{ppm}$ as mass error and $\pm 6 \mathrm{~s}$ as retention time error for feature grouping and matching. Moreover, MS/MS pattern of potential biomarkers were collected at the resolution of 70,000, the isolation width of $0.6 \mathrm{amu}$, IT of $100 \mathrm{~ms}$ and the collision energies of 10,20 and $30 \mathrm{eV}$. Pathway and enrichment analysis were conducted by MetaboAnalyst (http://www.metaboanalyst. ca/) [41].

\section{Targeted metabolomics and metabolic kinetic analysis}

Metabolites analyzed by targeted metabolomics included TCA cycle intermediates, related amino acids and polyamines (SRM transitions were shown in Supplementary Table 1). The data were acquired by Ultimate 3000 RSLC coupled to TSQ Quantiva ${ }^{\mathrm{TM}}$ triplequadrupole MS (QqQ, Thermo Scientific, USA). The Xbridge BEH Amide column $(2.1 \times 100 \mathrm{~mm}, 1.7 \mu \mathrm{m}$, Waters) was used for metabolites separation at $30^{\circ} \mathrm{C}$. Amino acids and polyamines were analyzed in positive ion mode, while the TCA cycle intermediates were analyzed in negative ion mode. Targeted kinetic isotope analysis was performed for polyamines and related amino acids of the TCA cycle and urea cycle. The SRM transitions involved ${ }^{12} \mathrm{C}$ - or ${ }^{13} \mathrm{C}$-labeled metabolites were shown in Supplementary Table 2. 


\section{Statistical analysis}

In the global metabolomics analysis, differential metabolites between DLD1-pLKO cells and DLD1shSLC25A22 cells were chosen by VIP over than 1 in the PLS-DA model and FC of shSLC25A22/pLKO more than 1.1 or less than 0.8 with significant differences $(p<$ 0.05 ) in Student's $t$-test. Additionally, the data for targeted metabolomics and targeted kinetic isotope analysis were performed as described [17].

\section{Western blot}

Total proteins were extracted using Cytobuster ${ }^{\mathrm{TM}}$ Protein Extraction Reagent (EMD Millipore), denatured in loading buffer, and then separated by sodium dodecyl sulfate polyacrylamide gel electrophoresis (SDS-PAGE). Antibodies for ODC (ab66067) and SAT1 (ab105220) were obtained from Abcam (Cambridge, MA).

\section{Quantitative PCR (qPCR)}

Total RNA was extracted using Trizol reagent, and cDNA was synthesized using the High-Capacity cDNA Reverse Transcription Kit (Thermo Fisher Scientific, Waltham, MA). PCR was performed using FastStart Universal SYBR Green Master Mix (Roche, Basel, Switzerland) in a LC480 LightCycler (Roche). The following primer sequences were used: $O D C$, forward: 5'- TTCCAAAGCAGTCTGTCGTCT-3' and reverse: 5'GGAAGCTGACACCAACAACAT-3'; SAT1, forward: 5'-CCGTGGATTGGCAAGT TATT $-3^{\prime}$ and reverse: 5'- TCCAACCCTCTTCACTGGAC-3'; and $\beta$-Actin, forward: 5'- AGAGCTACGAGCTGCCTGAC-3' and reverse: 5'- AGCACTGTGTTGGCGTA CAG-3'.

\section{3-(4,5-dimethylthiazol-2-yl)-2,5- diphenyltetrazolium bromide (MTT) assay}

Cell growth curve was performed using MTT assay (Sigma-Aldrich, St. Louis, MO). Briefly, DLD1 cells were seeded into 96 well plates $\left(1 \times 10^{3}\right.$ cells per well $)$ overnight, followed by the addition of polyamines for $48 \mathrm{~h}$. At the end of the incubation, MTT $(0.5 \mathrm{mg} / \mathrm{mL})$ was added to the medium for $4 \mathrm{~h}$, and the reaction was stopped by the addition of $0.1 \mathrm{~N} \mathrm{HCl}$ in $10 \% \mathrm{SDS}$. After overnight incubation, the plates are analyzed on a microplate reader $(570 \mathrm{~nm})$.

\section{Abbreviations}

CRC, Colorectal cancer; UHPLC, ultra-high performance liquid chromatography; NMR, nuclear magnetic resonance; MS, mass spectrometry; TIC, total ion chromatogram; TCA, tricarboxylic acid; QqQ, triplequadrupole; VIP, variable importance in projection;
PLS-DA, partial least squares-discriminant analysis; Gln, glutamine; Glu, glutamate; $\alpha-\mathrm{KG}, \alpha$-ketoglutarate; Suc, succinate; Fum, fumarate; Mal, malate; OAA, oxaloacetate; Cit, citrate; Isocit, isocitrate; Asp, aspartate; Asn, asparagine; Ala, alanine; Ser, serine; Gly, glycine; Orn, ornithine; Citr, citrulline; Arg, arginine; Pro, proline; AICAR, 1-(5'-Phosphoribosyl)-5-amino-4imidazolecarboxamide; Orn, ornithine; Citr, citrulline; Arg, arginine; Put, putrescine; Spd, spermidine; Spm, spermine; AcPut, $N^{l}$-acetylputrescine; AcSpd, $N^{I}$ acetylspermidine; AcSpm, $N 1$-acetylspermine; DAS, $N^{l}$, $N^{12}$-diacetylspermine; $O D C$, ornithine decarboxylase; SAT1, spermidine/spermine $N^{I}$ - acetyltransferase; ANSN, asparagine synthetase; 4-Cl-Phe, 4-chloro-phenylalanine; IS, internal standard; SRM, selected reaction monitoring; $\mathrm{RT}$, retention time.

\section{Author contributions}

$\mathrm{XL}, \mathrm{ZC}, \mathrm{CW}$ and $\mathrm{AC}$ designed the experiments; $\mathrm{XL}$ performed the experiments and drafted the manuscript, CW and JX cultured and collected the cell samples, SL contributed to the method development, LW contributed to metabolites identification, $\mathrm{AC}$ and JY contributed to biological interpretation and revised manuscript.

\section{ACKNOWLEDGMENTS}

The work is financially supported by the Interdisciplinary Research Matching Scheme (IRMS) of Hong Kong Baptist University (RC-IRMS/13-14/03), Collaborative Research Fund (CRF) of Research Grants Council (C2014-14E), General Research Fund of Research Grants Council (14114615) and National Natural Science Foundation of China (81502064). XL gratefully thanks the Hong Kong PhD Fellowship Scheme, Research Grant Council.

\section{CONFLICTS OF INTEREST}

The authors declare no conflicts of interest.

\section{REFERENCES}

1. Ferlay J, Soerjomataram I, Dikshit R, Eser S, Mathers C, Rebelo M, Parkin DM, Forman D, Bray F. Cancer incidence and mortality worldwide: Sources, methods and major patterns in GLOBOCAN. 2012. Int J Cancer. 2015; 136:E359-E86. https://doi.org/10.1002/ijc.29210

2. Tan $\mathrm{C}, \mathrm{Du} \mathrm{X}$. KRAS mutation testing in metastatic colorectal cancer. World J Gastroenterol. 2012; 18:5171-80. https://doi.org/10.3748/wjg.v18.i37.5171.

3. Hutchins G, Southward K, Handley K, Magill L, Beaumont C, Stahlschmidt J, Richman S, Chambers P, Seymour M, Kerr D, Gray R, Quirke P. Value of mismatch repair, KRAS, 
and BRAF mutations in predicting recurrence and benefits from chemotherapy in colorectal cancer. J Clin Oncol. 2011; 29:1261-70. https://doi.org/10.1200/JCO.2010.30.1366.

4. Wen Q, Dunne PD, O'Reilly PG, Li G, Bjourson AJ, McArt DG, Hamilton PW, Zhang SD. KRAS mutant colorectal cancer gene signatures identified angiotensin II receptor blockers as potential therapies. Oncotarget. 2017; 8:320625. https://doi.org/10.18632/oncotarget.13884.

5. Hsu HC, Thiam TK, Lu YJ, Yeh CY, Tsai WS, You JF, Hung HY, Tsai CN, Hsu A, Chen HC, Chen SJ, Yang TS. Mutations of KRAS/NRAS/BRAF predict cetuximab resistance in metastatic colorectal cancer patients. Oncotarget. 2016; 7:22257-70. https://doi.org/10.18632/ oncotarget.8076.

6. Xie H, Hou Y, Cheng J, Openkova MS, Xia B, Wang W, Li A, Yang K, Li J, Xu H, Yang C, Ma L, Li Z, et al. Metabolic profiling and novel plasma biomarkers for predicting survival in epithelial ovarian cancer. Oncotarget. 2017; 8:32134-46. https://doi.org/10.18632/oncotarget.16739.

7. Wong CC, Qian Y, Li X, Xu J, Kang W, Tong JH, To KF, Jin Y, Li W, Chen H, Go MY, Wu JL, Cheng KW, et al. SLC25A22 Promotes Proliferation and Survival of Colorectal Cancer Cells With KRAS Mutations, and Xenograft Tumor Progression in Mice, via Intracellular Synthesis of Aspartate. Gastroenterology. 2016. https://doi. org/10.1053/j.gastro.2016.07.011.

8. Poduri A, Heinzen EL, Chitsazzadeh V, Lasorsa FM, Elhosary PC, LaCoursiere CM, Martin E, Yuskaitis CJ, Hill RS, Atabay KD, Barry B, Partlow JN, Bashiri FA, et al. SLC25A22 is a novel gene for migrating partial seizures in infancy. Ann Neurol. 2013; 74:873-82. https://doi. org/10.1002/ana.23998.

9. Molinari F, Kaminska A, Fiermonte G, Boddaert N, RaasRothschild A, Plouin P, Palmieri L, Brunelle F, Palmieri F, Dulac O, Munnich A, Colleaux L. Mutations in the mitochondrial glutamate carrier SLC25A22 in neonatal epileptic encephalopathy with suppression bursts. Clin Genet. 2009; 76:188-94. https://doi.org/10.1111/j.13990004.2009.01236.x.

10. Wishart DS. Emerging applications of metabolomics in drug discovery and precision medicine. Nat Rev Drug Discov. 2016; 15:473-84. https://doi.org/10.1038/nrd.2016.32.

11. Weiss RH, Kim K. Metabolomics in the study of kidney diseases. Nat Rev Nephrol. 2011; 8:22-33. https://doi. org/10.1038/nrneph.2011.152.

12. Ulanovskaya OA, Zuhl AM, Cravatt BF. NNMT promotes epigenetic remodeling in cancer by creating a metabolic methylation sink. Nat Chem Biol. 2013; 9:300-6. https:// doi.org/10.1038/nchembio.1204.

13. Johnson CH, Dejea CM, Edler D, Hoang LT, Santidrian AF, Felding BH, Ivanisevic J, Cho K, Wick EC, Hechenbleikner EM, Uritboonthai W, Goetz L, Casero RA, et al. Metabolism Links Bacterial Biofilms and Colon Carcinogenesis. Cell Metabolism. 2015; 21:891-7. https://doi.org/10.1016/j. cmet.2015.04.011.

14. Patti GJ, Yanes O, Siuzdak G. Metabolomics: the apogee of the omics trilogy. Nat Rev Mol Cell Biol. 2012; 13:263-9. https://doi.org/10.1038/nrm3314.

15. Johnson $\mathrm{CH}$, Ivanisevic J, Siuzdak G. Metabolomics: beyond biomarkers and towards mechanisms. Nat Rev Mol Cell Biol. 2016; 17:451-9. https://doi.org/10.1038/ nrm.2016.25.

16. Chan EC, Pasikanti KK, Nicholson JK. Global urinary metabolic profiling procedures using gas chromatographymass spectrometry. Nat Protoc. 2011; 6:1483-99. https:// doi.org/10.1038/nprot.2011.375.

17. Li X, Wong CC, Tang Z, Wu J, Li S, Qian Y, Xu J, Yang Z, Shen Y, Yu J, Cai Z. Determination of amino acids in colon cancer cells by using UHPLC-MS/MS and [U-13C5]glutamine as the isotope tracer. Talanta. 2017; 162:285-92. https://doi.org/10.1016/j.talanta.2016.10.013.

18. Jose C, Hébert-Chatelain E, Bellance N, Larendra A, Su M, Nouette-Gaulain K, Rossignol R. AICAR inhibits cancer cell growth and triggers cell-type distinct effects on OXPHOS biogenesis, oxidative stress and Akt activation. Biochimica et Biophysica Acta (BBA) - Bioenergetics. 2011; 1807:70718. https://doi.org/10.1016/j.bbabio.2010.12.002.

19. Din FV, Valanciute A, Houde VP, Zibrova D, Green KA, Sakamoto K, Alessi DR, Dunlop MG. Aspirin inhibits mTOR signaling, activates AMP-activated protein kinase, and induces autophagy in colorectal cancer cells. Gastroenterology. 2012; 142:1504-15 e3. https://doi. org/10.1053/j.gastro.2012.02.050.

20. Wise DR, Thompson CB. Glutamine addiction: a new therapeutic target in cancer. Trends Biochem Sci. 2010; 35:427-33. https://doi.org/10.1016/j.tibs.2010.05.003.

21. Daye D, Wellen KE. Metabolic reprogramming in cancer: unraveling the role of glutamine in tumorigenesis. Semin Cell Dev Biol. 2012; 23:362-9. https://doi.org/10.1016/j. semcdb.2012.02.002.

22. Son J, Lyssiotis CA, Ying H, Wang X, Hua S, Ligorio M, Perera RM, Ferrone CR, Mullarky E, Shyh-Chang N, Kang Y, Fleming JB, Bardeesy N, et al. Glutamine supports pancreatic cancer growth through a KRAS-regulated metabolic pathway. Nature. 2013; 496:101-5. https://doi. org/10.1038/nature12040.

23. Gerner EW, Meyskens FL Jr. Polyamines and cancer: old molecules, new understanding. Nat Rev Cancer. 2004; 4:781-92. https://doi.org/10.1038/nrc1454.

24. Dang L, White DW, Gross S, Bennett BD, Bittinger MA, Driggers EM, Fantin VR, Jang HG, Jin S, Keenan MC, Marks KM, Prins RM, Ward PS, et al. Cancer-associated IDH1 mutations produce 2-hydroxyglutarate. Nature. 2009; 462:739-44. https://doi.org/10.1038/nature08617.

25. Xiao JF, Zhou B, Ressom HW. Metabolite identification and quantitation in LC-MS/MS-based metabolomics. Trends Analyt Chem. 2012; 32:1-14. https://doi.org/10.1016/j. trac.2011.08.009. 
26. Yuan M, Breitkopf SB, Yang X, Asara JM. A positive/ negative ion-switching, targeted mass spectrometrybased metabolomics platform for bodily fluids, cells, and fresh and fixed tissue. Nat Protoc. 2012; 7:872-81. https://doi.org/10.1038/nprot.2012.024.

27. Hirayama A, Kami K, Sugimoto M, Sugawara M, Toki N, Onozuka H, Kinoshita T, Saito N, Ochiai A, Tomita M, Esumi H, Soga T. Quantitative metabolome profiling of colon and stomach cancer microenvironment by capillary electrophoresis time-offlight mass spectrometry. Cancer Res. 2009; 69:4918 25. https://doi.org/10.1158/0008-5472.CAN-08-4806.

28. Nishiumi S, Kobayashi T, Ikeda A, Yoshie T, Kibi M, Izumi Y, Okuno T, Hayashi N, Kawano S, Takenawa T, Azuma T, Yoshida M. A Novel Serum MetabolomicsBased Diagnostic Approach for Colorectal Cancer. PLoS ONE. 2012; 7:e40459. https://doi.org/10.1371/ journal.pone.0040459.

29. Denkert C, Budczies J, Weichert W, Wohlgemuth G, Scholz M, Kind T, Niesporek S, Noske A, Buckendahl A, Dietel M, Fiehn O. Metabolite profiling of human colon carcinoma - deregulation of TCA cycle and amino acid turnover. Molecular Cancer. 2008; 7:72. https://doi.org/10.1186/1476-4598-7-72.

30. Sousa CM, Biancur DE, Wang X, Halbrook CJ, Sherman MH, Zhang L, Kremer D, Hwang RF, Witkiewicz AK, Ying H, Asara JM, Evans RM, Cantley LC, et al. Pancreatic stellate cells support tumour metabolism through autophagic alanine secretion. Nature. 2016; 536:479-83. https://doi.org/10.1038/ nature 19084

31. Krall AS, Xu S, Graeber TG, Braas D, Christofk HR. Asparagine promotes cancer cell proliferation through use as an amino acid exchange factor. Nat Commun. 2016; 7:11457. https://doi.org/10.1038/ncomms11457.

32. Toda K, Kawada K, Iwamoto M, Inamoto S, Sasazuki T, Shirasawa S, Hasegawa S, Sakai Y. Metabolic alterations caused by KRAS mutations in colorectal cancer contribute to cell adaptation to glutamine depletion by upregulation of asparagine synthetase. Neoplasia. 2016; 18:654-65. https://doi.org/10.1016/j. neo.2016.09.004.

33. Vargas AJ, Ashbeck EL, Wertheim BC, Wallace RB, Neuhouser ML, Thomson CA, Thompson PA.
Dietary polyamine intake and colorectal cancer risk in postmenopausal women. Am J Clin Nutrition. 2015; 102:411-9. https://doi.org/10.3945/ajen.114.103895.

34. Soda K. The mechanisms by which polyamines accelerate tumor spread. J Exp Clin Cancer Res. 2011; 30:95. https://doi.org/10.1186/1756-9966-30-95.

35. Goodwin AC, Shields CE, Wu S, Huso DL, Wu X, MurrayStewart TR, Hacker-Prietz A, Rabizadeh S, Woster PM, Sears CL, Casero RA. Polyamine catabolism contributes to enterotoxigenic Bacteroides fragilis-induced colon tumorigenesis. Proc Nat Aca Sci USA. 2011; 108:15354-9. https://doi.org/10.1073/pnas.1010203108.

36. Wang C, Ruan P, Zhao Y, Li X, Wang J, Wu X, Liu T, Wang S, Hou J, Li W, Li Q, Li J, Dai F, et al. Spermidine/spermine $\mathrm{N}(1)$-acetyltransferase regulates cell growth and metastasis via $A K T / \beta$-catenin signaling pathways in hepatocellular and colorectal carcinoma cells. Oncotarget. 2017; 8:1092-109. https://doi.org/10.18632/oncotarget.13582.

37. Dunn WB, Broadhurst D, Begley P, Zelena E, FrancisMcIntyre S, Anderson N, Brown M, Knowles JD, Halsall A, Haselden JN, Nicholls AW, Wilson ID, Kell DB, et al. Procedures for large-scale metabolic profiling of serum and plasma using gas chromatography and liquid chromatography coupled to mass spectrometry. Nat Protocols. 2011; 6:1060-83. https://doi.org/10.1038/ nprot.2011.335.

38. Smith CA, Want EJ, O'Maille G, Abagyan R, Siuzdak G. XCMS: processing mass spectrometry data for metabolite profiling using nonlinear peak alignment, matching, and identification. Analytical Chemistry. 2006; 78:779-87. https://doi.org/10.1021/ac051437y.

39. Bijlsma S, Bobeldijk I, Verheij ER, Ramaker R, Kochhar S, Macdonald IA, van Ommen B, Smilde AK. Large-scale human metabolomics studies: a strategy for data (pre-) processing and validation. Analytical Chemistry. 2006; 78:567-74. https://doi.org/10.1021/ac051495j.

40. Liu L, Wang M, Yang X, Bi M, Na L, Niu Y, Li Y, Sun C. Fasting serum lipid and dehydroepiandrosterone sulfate as important metabolites for detecting isolated postchallenge diabetes: serum metabolomics via ultra-high-performance LC-MS. Clin Chem. 2013; 59:1338-48. https://doi. org/10.1373/clinchem.2012.200527.

41. Xia J, Wishart DS. Using MetaboAnalyst 3.0 for comprehensive metabolomics data analysis. Curr Protoc Bioinformatics. 2016; 55:1401-09. https://doi.org/10.1002/ cpbi.11. 